\section{Case Reports in Neurology}

Case Rep Neurol 2020;12:365-372

DOI: 10.1159/000509681

Published online: October 30, 2020

c) 2020 The Author(s)

Published by S. Karger AG, Basel www.karger.com/crn

This article is licensed under the Creative Commons Attribution 4.0 International License (CC BY) (http://www.karger.com/Services/OpenAccessLicense). Usage, derivative works and distribution are permitted provided that proper credit is given to the author and the original publisher.

\title{
Guillain-Barré Syndrome Heralding the Diagnosis of Hodgkin Lymphoma: A Case Report
}

\author{
Alawi Aqel Al-Attas ${ }^{a} \quad$ Abdulrahman Yousef Aldayel $^{a}$ \\ Sara Abdullah Al Najjar ${ }^{b}$ Saleh Mansoor Alkhonezan ${ }^{c}$ \\ aDepartment of Neurology, Prince Sultan Military Medical City, Riyadh, Saudi Arabia; \\ ${ }^{b} K i n g$ Abdulaziz Medical City, National Guard Hospital, Riyadh, Saudi Arabia; 'College of \\ Medicine, Imam Mohammad Ibn Saud Islamic University (IMSIU), Riyadh, Saudi Arabia
}

\section{Keywords}

Guillain-Barré syndrome · Hodgkin's lymphoma · Neuropathy · Lymphoma

\begin{abstract}
Lymphoma is a prevalent type of lymphoid tissue malignancy that is seldom associated with Guillain-Barré syndrome (GBS). In the majority of instances, both Hodgkin's and nonHodgkin's lymphoma are not proceeded by GBS. Here, we report on a case of a young patient with a manifestation and investigation suggestive of GBS, signaling an unconfirmed diagnosis of Hodgkin's lymphoma. A cerebrospinal fluid test revealed an albuminocytological dissociation with a noteworthy rise in protein $(2.32 \mathrm{~g} / \mathrm{L})$. The patient was initiated on intravenous immunoglobulin (IVIG) treatment and then showed dramatic improvement after the third dose of IVIG. His constitutional presentation alongside high inflammatory labs prompted further investigation. An enhanced pan-computed tomography scan showed multiple enlarged mediastinal and hilar lymph nodes that were confirmed as Hodgkin's lymphoma after biopsy. Brentuximab was initiated immediately after IVIG therapy. This case
\end{abstract}




\section{Case Reports in Neurology}

Case Rep Neurol 2020;12:365-372

DOI: 10.1159/000509681

(C) 2020 The Author(s). Published by S. Karger AG, Basel www.karger.com/crn

Al-Attas et al.: GBS Heralding the Diagnosis of Hodgkin Lymphoma

highlights consideration of Hodgkin's lymphoma as a differential diagnosis under the auspices of GBS.

(C) 2020 The Author(s)

Published by S. Karger AG, Basel

\section{Introduction}

Lymphomas are a type of malignancy that results from abnormally growing lymphoid tissue [1]. They have two main types - Hodgkin's and non-Hodgkin's variants - and are differentiated by the presence of Reed-Sternberg cells [1]. The neurological manifestations associated with lymphomas are unusual and often do not present until advanced stages of the disease. The neurological abnormalities are generally attributed to invasion of the nerves, complications or side effects of radiotherapy and chemotherapy, compression by a mass, infection, or as a presentation of paraneoplastic syndrome (PNS) [2,3].

Guillain-Barré syndrome (GBS) is an acute inflammatory demyelinating polyradiculoneuropathy caused by demyelination and axonal loss of peripheral nerves leading to progressive, acute, and ascending weakness; the absence of deep tendon reflexes; and abnormal sensation secondary to the inflammatory process that causes this neuropathy [4]. It is considered to be one of the common causes of acute muscle flaccid paralysis [5]. GBS is diagnosed by a combination of clinical findings, laboratory tests, and neurophysiological exams [4]. Clinically, it varies from mild-moderate presentations to severe and deadly paralysis [6]. For both types of lymphoma, PNS featuring the GBS variant is rare [7, 8]. However, GBS is more prevalent in non-Hodgkin's lymphoma than in Hodgkin's lymphoma [9]. In this study, we report on a rare case of a young male who has Hodgkin's lymphoma complicated by GBS.

\section{Case Report}

The patient is a 19-year-old Saudi male with no medical complaints. On August 27, 2018, he developed a productive cough, for which he sought medical attention at multiple local hospitals. He was initially diagnosed with bronchial asthma and treated with nebulization using salbutamol (Ventolin). Later on, he developed a fever with fatigue and night sweats that was unresponsive to antipyretics. On December 11,2018, he was referred to Prince Sultan Military Medical City, Riyadh, Saudi Arabia, and was admitted to the pulmonology service as a case of pulmonary tuberculosis (TB) versus lymphoma for further evaluation. A chest X-ray showed an opacification in the right middle lobe and a widened mediastinum. Laboratory tests exhibited elevated inflammatory markers; an elevated erythrocyte sedimentation rate of $48 \mathrm{~mm} / \mathrm{h}$, and an elevated c-reactive protein of $169 \mathrm{mg} / \mathrm{L}$. An enhanced pan-computed tomography (CT) showed multiple enlarged mediastinal and hilar lymph nodes that were likely to be lymphoma and required further evaluation (Fig. 1,2), and for this reason, a biopsy was taken from a palpable cervical lymph node; while awaiting the results, the patient was referred to the Neurology Department after experiencing sudden facial weakness and difficulty with speech. A brain CT was done, but it displayed no ischemic changes or bleeding. A few days later, he developed gradual symmetrical bilateral lower limb weakness followed by symmetrical bilateral upper 


\section{Case Reports in Neurology}

Case Rep Neurol 2020;12:365-372

DOI: 10.1159/00050968

(C) 2020 The Author(s). Published by S. Karger AG, Basel www.karger.com/crn

Al-Attas et al.: GBS Heralding the Diagnosis of Hodgkin Lymphoma

limb weakness and bulbar symptoms (slurred speech, dysphagia, and drooling). He also complained of severe back pain, proximal thigh pain, and a headache. There was no history of sphincter dysfunction, loss of consciousness, abnormal movement, visual changes, gastrointestinal symptoms, or previous similar episodes. The results of the lymph node's biopsy were consistent with Hodgkin's lymphoma.

A neurological examination on the same day as he developed the weakness and bulbar symptoms was described as follows.

The patient is anxious, dysarthric, with continuous drooling of saliva. Cranial nerve examination was normal except for evidence of facial diplegia with normal gag reflex and no dysphagia.

Examination of the upper and lower limbs revealed decreased tone with an absence of reflexes and sensation to pinprick, pain, temperature, vibration, and proprioception. There was no sensory level.

His weakness was more pronounced in the lower limbs: 2/5 for hip flexion, extension, abduction, adduction, knee flexion, extension, ankle plantar flexion, and dorsiflexion. The upper limbs yielded $4 / 5$ for shoulder abduction, adduction, elbow flexion, extension, wrist flexion, and extension. Examination of his gait and a full cerebellar examination were difficult to perform given the weakness described above.

Subsequently, a lumbar puncture was done, and his cerebrospinal fluid showed an albumin cytological dissociation (Table 1). Three samples of sputum culture for TB and a stool culture for Campylobacter, Salmonella and Shigella were negative. Thyroid function tests, folate, and vitamin $B_{12}$ were normal, and his EBV IgG was positive. His EBV IgM and HIV serology were negative.

A nerve conduction study was done 14 days post-onset of the presentations, and it showed that the sensory nerve action potential for the ulnar, median, radial, and sural nerves was absent. On the other hand, the compound muscle action potential for ulnar, median tibial and peroneal nerves are normal in amplitude as well as normal conduction velocity. $\mathrm{F}$ waves for median and tibial nerves are within normal limit. Electromyography of the tibialis anterior and gastrocnemius exhibited reduced activation of all the aforementioned nerves, collectively suggesting GBS. At this point, the patient was started on $2.5 \mathrm{~g}(0.4 \mathrm{mg} / \mathrm{kg})$ intravenous immunoglobulin (IVIG) daily for 5 days. After that, there was a significant improvement: his strength improved in his proximal limbs from $4 / 5$ in the upper limbs to $5 / 5$ and from $2 / 5$ in the lower limbs to 3/5. From the oncological side of his treatment, the patient was started on Brentuximab $1.8 \mathrm{mg} / \mathrm{kg}$ intravenous immediately after the first dose of IVIG, and it was planned to be given every 3 weeks for a total of 16 cycles.

\section{Discussion}

PNS is a remote effect of cancer on the central nervous system (CNS); hence, the neurological presentations are not attributed directly or partially to the underlying CNS tumor effect alongside it is not enlightened by any tumor metastasis, side effects of tumors medications, or opportunistic infections of the CNS [10]. Most cases of PNS arise via autoimmune processes [10]. Consequently, the evolution of the autoimmune mechanism has an analogous antigenic property among the underlying cancer via either the central or peripheral nervous system, 


\section{Case Reports in Neurology}

Case Rep Neurol 2020;12:365-372

DOI: 10.1159/00050968

(C) 2020 The Author(s). Published by S. Karger AG, Basel www.karger.com/crn

Al-Attas et al.: GBS Heralding the Diagnosis of Hodgkin Lymphoma

which explains its pathogenesis. To confirm diagnosis, neuronal autoantibodies are detected and counted; however, the absence of these autoantibodies does not exclude a diagnosis of PNS $[10,11]$. The incidence of PNS with lymphoma is quite rare. Both the symptoms and the rate of recurrence of neurological PNS differ between Hodgkin's lymphoma and non-Hodgkin's lymphoma. While cerebellar syndromes and limbic encephalitis are widely linked to Hodgkin's lymphoma, sensory neuropathy and motor system involvement are detected more often in non-Hodgkin's lymphoma and only very infrequently in Hodgkin's lymphoma $[11,12]$. Although GBS has been variably related with Hodgkin's lymphoma in previous case reports [8, 13-18], almost all of these were in the form of previously diagnosed cases of Hodgkin's lymphoma.

GBS is known to follow certain viral illnesses such as cytomegalovirus, influenza virus, Epstein-Barr virus, and perhaps many others [19]. Variable grades of reduced immunity, mainly of the cell-mediated type, are known to trail these viral illnesses [20]. The similar mechanism may also be functional in other circumstances of noticeable drops in immunity that have been related to GBS attacks (e.g., diabetes mellitus, systemic lupus erythematosus, postoperative patients, and pregnant women) [19]. This mechanism may also be involved in the presence of lymphoma, which alters the patient's state of immunity depending on the different types of malignancies that are present.

The initial case report of a hypothetical association of GBS with Hodgkin's lymphoma took place in a young male patient in whom the presentations of GBS came after he was diagnosed with Hodgkin's lymphoma of 6 years [15]. Lisak et al. [13] reported a case study series in which the patients had a known diagnosis of Hodgkin's lymphoma and developed GBS later on. They found that the patients presented with GBS when they were relapsing or when they were undergoing chemotherapy. Likewise, after their clinical and pathological research on GBS and Hodgkin's lymphoma, Julien et al. [14] reported a case of GBS in a patient with a relapsed phase of Hodgkin's lymphoma. Both Anderson et al. [21] and Cabot et al. [16] (the latter from a case at Massachusetts General Hospital in the United States) revealed that GBS immediately preceded Hodgkin's lymphoma, as in the present case. However, in comparison with the other previously reported cases, in this case, our patient manifested a more severe form of GBS in term of muscle power, and it was more acute to have GBS presentation after the confirmation of Hodgkin's type lymphoma.

GBS is usually treated with a 5-day course of IVIG to suppress disease progression; GBS can injure and cause permanent damage to the peripheral nervous system [22]. In our patient, his condition deteriorated when IVIG was first started. This occurrence was reported in two similar cases of patients with GBS after they were diagnosed with lymphoma $[8,20]$. The medical indication is that the disease is atypically manifested. In contrast, the neurological presentations of these patients greatly improved upon commencement of the chemotherapeutic agents intended for lymphoma abolition, as mentioned in previous studies [8, 20]. The assumed reason that patients do not respond to IVIG monotherapy in Hodgkin's lymphoma is that the mechanism comparations among idiopathic GBS and Hodgkin's lymphoma-induced GBS are still uncertain. However, treatment for Hodgkin's lymphoma as the underlying provocation of GBS seems essential.

For many cases of PNS, full recovery from the neurological symptoms will not ensue despite the removal of the causative tumor; this is attributed to an autoimmune mechanism [3]. After treatment, the outcomes of PNS-related Hodgkin's lymphoma vary. In some cases, the 


\section{Case Reports in Neurology}

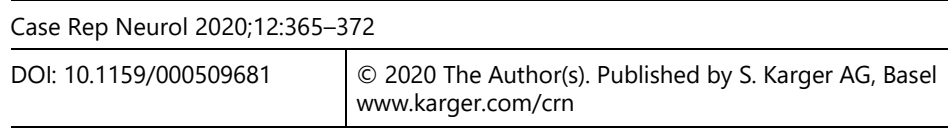

Al-Attas et al.: GBS Heralding the Diagnosis of Hodgkin Lymphoma

neurological presentations did not improve after treatment for lymphoma, whereas in some patients, these symptoms increased after initiating chemotherapy [23]. Nevertheless, IVIG treatment was given to our patient, but he was not started on chemotherapy because the GBS preceded the diagnosis of lymphoma. Significant improvements were noticed after the second dose of IVIG, and even more after the third dose. GBS improvement was not affected by the later initiation of chemotherapeutic agents.

To conclude, it is very rare for lymphoma to cause GBS, especially Hodgkin's lymphoma. The GBS in this case was secondary to Hodgkin's lymphoma, as previous studies have supported. Our case is peculiar, as GBS preceded and heralded the diagnosis of Hodgkin's lymphoma. This could influence the potential autoimmune mechanisms as a pathophysiology for this association. Additional studies are required to verify the pathophysiology of this disease; at this point, GBS could be considered as a significant differential diagnosis of neurological manifestations preceding or following Hodgkin's lymphoma.

\section{Acknowledgment}

The authors would like to thank the patient and his family for agreeing to participate in this study.

\section{Statement of Ethics}

The patient provided both oral and written consent to publish this case with the images.

\section{Conflict of Interest Statement}

The authors would like to declare that they have no competing interests or anything to disclose.

\section{Funding Sources}

There was no funding given to support this study.

\section{Author Contributions}

Alawi Al-Attas (the principal author), he was the one who took the history and examined our patient, interpreted the data, and reviewed the initial draft of manuscript as well as contributed in writing and revision of the final draft of manuscript. Abdulrahman Aldayel wrote the initial draft of manuscript, contributed to data collection and review the final draft of the manuscript. Sara Al Najjar assessed the patient together with Dr. Al-Attas and reviewed the 


\section{Case Reports in Neurology}

Case Rep Neurol 2020;12:365-372

DOI: 10.1159/00050968

(c) 2020 The Author(s). Published by S. Karger AG, Basel www.karger.com/crn

Al-Attas et al.: GBS Heralding the Diagnosis of Hodgkin Lymphoma

final draft of the manuscript. Saleh Mansoor Alkhonezan helped in writing the manuscript and reviewed the final draft of the manuscript.

\section{References}

1 Friedman DL. Hodgkin lymphoma. In: Lanzkowsky P, Lipton JM, Fish JD, editors. Lanzkowsky's manual of pediatric hematology and oncology. 6th ed. Amsterdam: Elsevier; 2016. pp. 429-41.

2 Correale J, Monteverde DA, Bueri JA, Reich EG. Peripheral nervous system and spinal cord involvement in lymphoma. Acta Neurol Scand. 1991 Jan;83(1):45-51.

3 Flanagan EP, Sandroni P, Pittock SJ, Inwards DJ, Jones LK Jr. Paraneoplastic lower motor neuronopathy associated with Hodgkin lymphoma. Muscle Nerve. 2012 Nov;46(5):823-7.

4 Dimachkie MM, Barohn RJ. Guillain-Barré syndrome and variants. Neurol Clin. 2013 May;31(2):491-510.

5 Jasem J, Marof K, Nawar A, Khalaf Y, Aswad S, Hamdani F, et al. Guillain-Barré syndrome as a cause of acute flaccid paralysis in Iraqi children: a result of 15 years of nation-wide study. BMC Neurol. 2013;13:195. doi: https://doi.org/10.1186/1471-2377-13-195

6 Winer JB. Guillain Barré syndrome. Mol Pathol. 2001 Dec;54(6):381-5.

7 Kelly JJ, Karcher DS. Lymphoma and peripheral neuropathy: a clinical review. Muscle Nerve. 2005 Mar;31(3):301-13.

8 Viala K, Béhin A, Maisonobe T, Léger JM, Stojkovic T, Davi F, et al. Neuropathy in lymphoma: a relationship between the pattern of neuropathy, type of lymphoma and prognosis? J Neurol Neurosurg Psychiatry. 2008 Jul;79(7):778-82.

9 Al IO, Koç B, Bayram C,Paslı EU, Yıldız EP, Ayçiçek A, et al. Variant Guillain-Barré syndrome in a patient with Hodgkin lymphoma: AMSAN. Turk Pediatri Ars. 2018;53(4):263-266. doi: https://doi.org/10.5152/TurkPediatriArs.2018.4763

10 Tüzün E. Nörolojik tutulumla seyreden paraneoplastik sendromlar. Klinik Gelișim Dergisi. 2010;23:71-7.

11 Graus F, Ariño H, Dalmau J. Paraneoplastic neurological syndromes in Hodgkin and non-Hodgkin lymphomas. Blood. 2014 May;123(21):3230-8.

12 Polo-Romero FJ, Sánchez-Beteta P, Perona-Buendía P, Pérez-García AM. Guillain-Barré syndrome as first presentation of non-Hodgkin lymphoma. Neurologia. 2012 Oct;27(8):511-3.

13 Lisak RP, Mitchell M, Zweiman B, Orrechio E, Asbury AK. Guillain-Barré syndrome and Hodgkin's disease: three cases with immunological studies. Ann Neurol. 1977 Jan;1(1):72-8.

14 Julien J, Vital C, Aupy G, Lagueny A, Darriet D, Brechenmacher C. Guillain-Barré syndrome and Hodgkin's disease-ultrastructural study of a peripheral nerve. J Neurol Sci. 1980 Feb;45(1):23-7.

15 Cameron DG, Howell DA, Hutchison JL. Acute peripheral neuropathy in Hodgkin's disease; report of a fatal case with histologic features of allergic neuritis. Neurology. 1958 Jul;8(7):575-7.

16 Cabot RC, Scully RE, Mark EJ, McNeely WF, McNeely BU, Cros D, et al. Case records of the Massachusetts General Hospital. Weekly clinicopathological exercises. Case 39-1990. A 66-year-old man with demyelinative neuropathy and a retroperitoneal mass. N Engl J Med. 1990 Sep;323(13):895-908.

17 Amundson DE, Goodman JC. Hodgkin's disease in association with Guillain-Barre-Strohl syndrome: case report. Mil Med. 1983 Jun;148(6):512-3.

18 Cuttner J, Meyer R. Guillain-Barré syndrome in a patient with Hodgkin's disease. Mt Sinai J Med. 1978 MayJun;45(3):415-7.

19 Willison HJ, Jacobs BC, van Doorn PA. Guillain-Barré syndrome. Lancet. 2016 Aug;388(10045):717-27.

20 Maggini S, Pierre A, Calder PC. Immune Function and Micronutrient Requirements Change over the Life Course. Nutrients. 2018 Oct;10(10):17.

21 Anderson D, Beecher G, Steve TA, Jen H, Camicioli R, Zochodne DW. Neurological Nuance: hodgkin lymphoma presenting with Guillain-BarrÉ syndrome. Muscle Nerve. 2017 Apr;55(4):601-4.

22 van Doorn PA, Ruts L, Jacobs BC. Clinical features, pathogenesis, and treatment of Guillain-Barré syndrome. Lancet Neurol. 2008 Oct; 7(10):939-50.

23 Forsyth PA, Dalmau J, Graus F, Cwik V, Rosenblum MK, Posner JB. Motor neuron syndromes in cancer patients. Ann Neurol. 1997 Jun;41(6):722-30. 


\section{Case Reports in Neurology}

\begin{tabular}{l|l}
\hline Case Rep Neurol 2020;12:365-372 \\
\hline DOI: 10.1159/000509681 & $\begin{array}{l}\text { @ 2020 The Author(s). Published by S. Karger AG, Basel } \\
\text { www.karger.com/crn }\end{array}$ \\
\hline
\end{tabular}

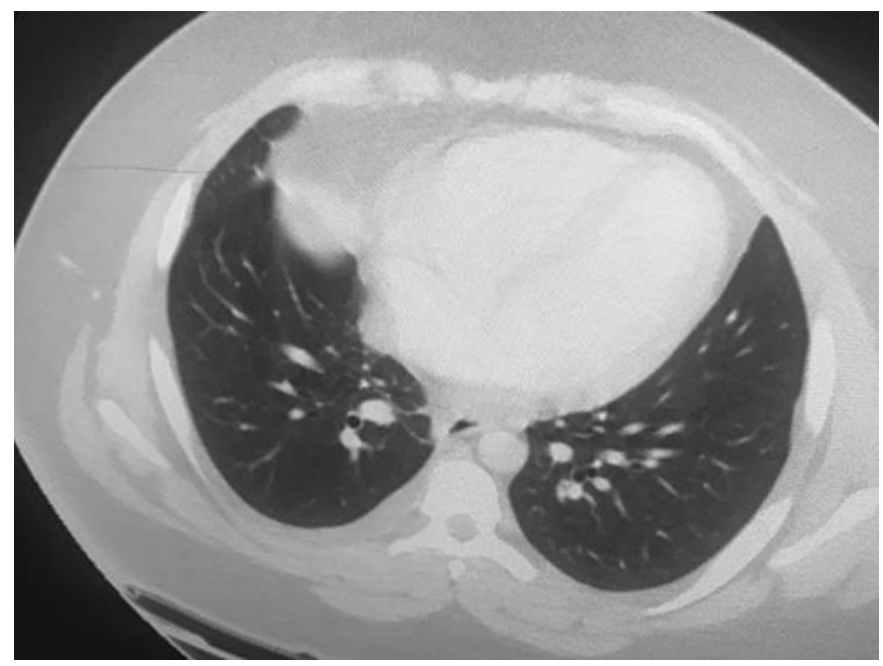

Fig. 1. Axial CT scan of the chest demonstrates multiple scattered mass-like lesions in both lungs, with airbronchogram inside.

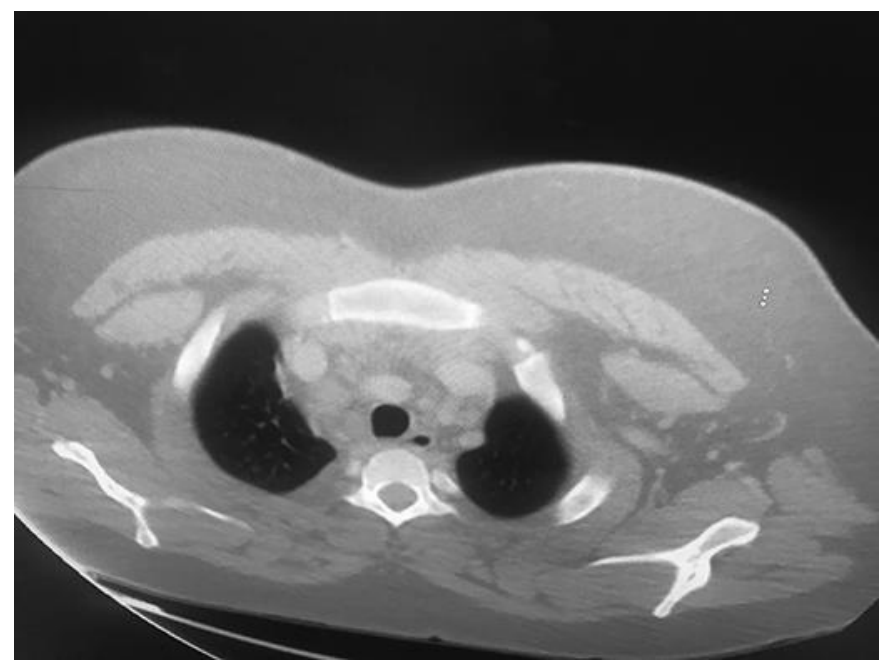

Fig. 2. Axial view of the chest of the same patient with multiple enlarged upper mediastinal and hilar lymph nodes. 
Case Reports in

Neurology
Case Rep Neurol 2020;12:365-372

\begin{tabular}{l|l}
\hline DOI: $10.1159 / 000509681$ & ๑ 2020 The Author(s). Published by S. Karger AG, Basel \\
\hline
\end{tabular} www.karger.com/crn

Al-Attas et al.: GBS Heralding the Diagnosis of Hodgkin Lymphoma

Table 1. Results of laboratory analysis of CSF sample

\begin{tabular}{lll}
\hline Test & Result & Normal value \\
\hline CSF protein & $2.32 \mathrm{~g} / \mathrm{L}$ & $0.18-0.58 \mathrm{~g} / \mathrm{L}$ \\
CSF WBC & 5 cells/CUMMa & $0-5$ cells/CUMMa \\
CSF cytology & Negative & \\
CSF AFB $^{*}$ & Negative & \\
CSF PCR Tb $^{\#}$ & Negative & \\
Paraneoplastic panelx & Negative & \\
Protein electrophoresis & Marked decrease in gamma globulin \\
Protein immunofixation & Negative \\
\hline
\end{tabular}

a Cubic millimeter. * Acid-Fast Bacilli. \# Polymerase chain reaction for tuberculosis. x Paraneoplastic panel including (Hu abs, Ri abs, Yo abs, CV2/CRMP5 abs, ANNA 3 abs, and Tr abs). 